EPiC Series in Education Science
Volume 2, 2019, Pages 1-17
$\begin{gathered}\text { Proceedings of Learning Innova- } \\ \text { tions and Quality (LINQ) 2019 }\end{gathered}$

\title{
Towards Growth-Mindset Mathematics Teaching in the Netherlands
}

\author{
Greg Alpar ${ }^{1,2 *}$ and Marloes van Hoeve ${ }^{3,4 \uparrow}$ \\ ${ }^{1}$ Open University of the Netherlands \\ ${ }^{2}$ Radboud University, The Netherlands \\ ${ }^{3}$ Goois Lyceum, Bussum, The Netherlands \\ ${ }^{4}$ Utrecht University, The Netherlands \\ greg.alpar@ou.nl, mvhoeve@gsf.nl
}

\begin{abstract}
Mathematics is the foundation of sciences and it is important in a learner's career success. Growth mindset in mathematics teaching is essential to reach a broader student population effectively. Shifting the focus from performance and time pressure to deep understanding and personal growth, unnecessary competition vanishes among learners. As a result, they develop a better relation with their own thinking and they gain insights into the thinking of others. At the same time, collaboration and communication emerge naturally. The fear of mathematics and making mistakes disappear, while students learn by connecting ideas and applying the already learned study material.

In the academic years of 2017-2018 and 2018-2019, two Dutch research projects dealt with the application of a growth mindset in mathematics teaching. One was in secondary schools, the other one at universities. In this article, we briefly report about and reflect on the exciting results of these studies and suggest further directions for research and the development of best practices.

The ideas and experiences described in this paper are urgent as currently we are at the threshold of a new era in which education and learning are (and should be) really open for everyone; with low floor and without ceilings.
\end{abstract}

\section{Introduction}

There is a shift in mathematics teaching. Students start to look forward to learning more mathematical ideas and teachers start to curiously listen to the valuable mathematical discussions in the classroom. Students feel responsible for their own learning process and work hard to find good strategies to solve problems. This shift is caused by Jo Boaler's Mathematical Mindsets (Boaler, 2016),

* The research is partly supported by NRO Comenius Programme 2018.

${ }^{\dagger}$ The research was partly carried out within the Post-doc VO programme. 
which in turn is based on Carol Dweck's findings with regard to growth mindset (Dweck, 2006). This is indeed a major shift if compared to classrooms that mathematics is usually associated with: a mathematics class traditionally involves students who learn methods from the teacher, practice them, and are then being tested. This article explores the impact of this possible shift in various classroom settings (in The Netherlands) and puts forward ideas for future theoretical and practical work.

To demonstrate the result of the traditional education and the need for the shift described above, let us start with two short stories. One of the authors observed a mathematics lecture at a computer science department in the Netherlands in 2015. Sitting in the last row, he had a perfect view what students did while the professor was presenting the new material. What struck him was that the most interesting ideas and reasoning, though explained intriguingly, were clearly uninteresting for students. They only paid attention to the calculation examples, that were expected to be similar to some homework or exam problems.

In the same year, he himself taught cryptography, a subject that thoroughly applies mathematics. Students were very interested in the topics, as many followed the programme oriented towards cybersecurity, of which cryptography is a fundamental building block. Therefore, they tried to grasp everything. During the exercise sessions, students could solve problems that followed the same structure as the ones during the lecture. However, when a problem required additional thinking, some creative strategy or collaborative work, most students got stuck. When analyzing the possible solutions, they were surprised. Seeing the ideas, some students even commented "Are we allowed to do that?" or "We didn't learn any formula for this problem".

Mathematics, as later several interviews with bachelor students confirmed, is often viewed as a set of formulas and methods that one has to learn and apply. For students, mathematics is not about complex problem solving or logical reasoning. Mathematics is "computation on paper", as one student phrased it very concisely during a class discussion. Being asked further, he explained that "the same computation implemented in a computer is not mathematics anymore".

By the time they arrive at the university, students have already developed an image about mathematics and about their place and ability within mathematics. Many are afraid of it, and doubt their own capacities. This relates to the (often implicit) strong association between mathematics and intelligence in our society, like "If I am not good at maths, I am probably not intelligent."

As mathematics is the foundation of sciences and it is applied in so many fields, it is important that mathematics is available for everybody in the modern world. The skills of recognizing regularities, handling numerical expressions, making and comparing estimates, and reasoning logically are required for nearly all jobs and for our daily lives. Despite this demand, people are often afraid of mathematics in whatever form it appears. Mathematics education has been in many respects unchanged in the last centuries. Pupils and students have to memorize and practice procedures without sense-making. As a result, problem situations involving uncharted territories or unknown formulations, appear as a threat to many.

Growth mindset plays a central role in this change. Research indicates that, by communicating that learners can always grow, that they can always develop new abilities and strategies, students start to work with more enthusiasm and curiosity (Dweck, 2006, Boaler, 2016). Important aspects are that learners are not inhibited by imaginary boundaries and that they focus less on protecting their intelligence or talents.

The question that we ask in this article is how a growth-mindset shift in teaching affects mathematics learning. In particular, this work considers two educational levels. First, it describes the research based on interventions carried out in 10 secondary schools in The Netherlands. The research started with an information meeting for the teachers in which they learned and experienced how the intervention worked. After this session, the research consisted of several interventions during four lessons in a period of approximately two months. The aim was to improve the motivation and enthusiasm with which the students carry out mathematical tasks. 
The other education level that this article focuses on is the university level. We developed an introductory course into mathematics learning which was provided for computer science students at the beginning of their studies. The objective was two-fold. It aimed to change the attitude of students towards mathematics (based on growth mindset) and it provided an initial toolset to learn mathematics with openness. This latter includes the exploratory nature of mathematics and the usefulness and joy with regard to problem solving. The course, called the Open Maths course, was given at two different Dutch universities - one at a traditional university (Radboud University) and the other one at the Open University of the Netherlands, a university that focuses on life-long learning, self-study, and online classes. The goal was to make students enthusiastic about mathematics and much less concerned about their talents.

In the rest of this paper we present some results of the two studies. Our aim is not to describe and analyze all elements in detail, but to give an overview what has been done and to focus on the important consequences of our research. We are convinced that mathematics teaching, with mathematics' many dimensions and with the huge potential of the human mind that every student possesses, can be efficient and rewarding. Additionally, while teaching with a growth mindset, we ourselves experienced how much we can learn from students, while expanding our own competences.

\section{Growth mindset in mathematics learning}

Recent neuroscience and psychology research shows important facts about our learning abilities. Neuroplasticity is the brain's ability to change throughout our lives so that our mental capacities can be extended (Draganski, Gaser, Busch, Schuierer, Bogdahn, \& May, 2004, Woollett \& Maguire, 2011). The research of Stanford psychology professor Carol Dweck (Dweck, 2006) has demonstrated that people think differently about self-development. People with a fixed mindset believe that their intelligence and other talents are gifts by birth, whereas people with a growth mindset focus on their progress. One's mindset has a profound effect on learning. Focusing on talent, one chooses strategies that are well-known for them and avoids challenges. This is because a hard problem that cannot be solved instantly sends an implicit message to this person that they are not talented in that area. On the other hand, focusing on growth, one is willing to be challenged as one discerns such situations as a chance to develop. Dweck has also discovered that a fixed mindset can be changed to a growth mindset at all times (so also for adults) and in all fields (including sports, education, management and relationships) to achieve successful learning.

Similarly, growth mindset can also be encouraged in mathematics (Boaler, 2016). Students who seek challenges and believe that they can evolve, will be able to learn. They are able to think deeply, to discover patterns and relations, to put forward conjectures and to test and prove them. These skills (Polya, 1957, Drijvers, 2015) are beneficial for students, already at the secondary-school level and increasingly more at university subjects (such as calculus, discrete mathematics, linear algebra). Also, more importantly, they are useful in their career, which takes place in a challenging future, full of uncertainties, new professions and ever improving computing capability and artificial intelligence.

Although mathematics is highly regarded in the society, it is often associated with something you are either good at or not (Koncepciya razvitiya, 2013, Larina \& Markina, 2019). These two aspects together result in fixed-mindset ideas about mathematics: it is difficult and only for gifted people. Therefore, good marks for mathematics are often seen as clear evidence for being intelligent. Mathematics can give students much frustration when they are not able to solve a problem right away; they feel immediately that they are not smart enough.

Mathematics is a subject of which there is a very fixed idea in society. On the one hand, many authors remark that they are not good at mathematics. Notably, they never talk about being bad at other subjects, such as geography or history; see e.g. (Isik, 2017). On the other hand, there are many stories 
of people on the autism spectrum disorder (ASD) being fond of mathematics; see e.g. (Haddon, 2003): "Mr. Jeavons said I liked math because it was safe. He said I liked math because I could solve problems, and those problems were difficult and interesting, but there was always a clear solution." The film industry also reinforces the fixed-mindset idea about mathematics with movies such as "The Man Who Knew Infinity" and "A Beautiful Mind". These works are about brilliant men (almost never women) and a mathematics that is only for the geniuses. In their study on the mathematical mindsets of students and teachers, Anderson, Boaler, \& Dieckmann (2018) conclude that there is a growing awareness to change the myth that people are born as math people; they conclude that this is one of the most important responsibilities for educators.

Therefore, it is time for a collective change about mathematics because the current fixed image can strengthen a fixed mindset in students. Students with a growth mindset can enjoy mathematics, dare to try and fail and rise again, think deeply, and ask many questions. The society needs this since mathematics is an important fundament of technology, economics, trade, etc. Also, mathematics brings additional benefits; while doing mathematics, students learn to give logical arguments, they learn about their own thinking process, and they learn to persevere in the presence of frustration. As a result, they are increasingly more conscious about how they develop. The Dutch word for mathematics is wiskunde, which is "the art of being certain". Certainty can be achieved by convincing others and yourself. Mathematics - already at the most basic levels - offers many opportunities "to convince yourself, a friend and a skeptic" that your thinking makes sense (Boaler, 2016). In sum, there is much room for improvement for teachers, classes, schools, and for society.

This change is not only timely, but it is also possible according to research about achievement and neuroscience. Mindset intervention also has an impact on marks, as shown in a recent study in Australia (Bostwick, Martin, Collie, \& Durksen, 2019). Students' growth orientation in mathematics was a significant positive predictor of students' gains in mathematics engagement and achievement. Above other sources of influence, the marks rise as a result of different types of growth constructs, including growth mindset and growth goals (self-based and task-based). Recent neuroscience studies also show the effect of changes in mindset and motivation. A small change in mathematical tasks using Boaler's mathematical mindsets approach (Boaler, 2016) resulted in a clear rise in motivation levels as shown by EEG scans of students' brains (Daly, Bourgaize, \& Vernitski, 2019). If such minor adaptations can already result in measurable changes in the brain, how promising can it be to try to adjust activities more extensively according to the mathematical mindset theory and with the explanation of Dweck's mindset theory?

\section{Need for change}

The current view on mathematics became very evident from the Open Math course. An important element of this course is the very first homework. Students had to write their own "Mathematics history", in which they reflected on their prior experiences in mathematics and within the mathematics education. In these stories some clear patterns arose. Students talked about pressure, the lack of creativity and real challenges, the focus on marks, and the little attention on motivation. For instance, questions like "Why is this important for me?" or "Why does this formula work?" were rarely discussed or questioning was even discouraged. Nevertheless, there were some positive memories as well. Students often appreciated the applicability of mathematics, enthusiastic teachers, and the satisfactory feeling of successful computation. Additionally, some good memories are related to good marks. So, students enjoyed understanding, good communication and having finished a problem, but they had few positive experiences and these were typically narrower than what mathematics generally has to offer.

The need to change does not only concern recent education but also future careers. As technology is developing at an ever-increasing pace, new kinds of learning and teaching strategies are necessary. 
Technology changes the job market. Old jobs become obsolete as computers are taking over the tasks from humans and new jobs are evolving to satisfy novel demands. Future generations need to find their places in this volatile environment with willingness to develop and with life-long learning capacities (Van Merriënboer \& Kirschner, 2012). The five most anticipated emerging skills (World Economic Forum, 2018) - creativity, analytical thinking, learning strategies, technology design and programming, and complex problem-solving - are all closely related mathematics. Besides the changing job market, the possibilities are also expanding on the Internet - a flagship technological invention itself. New communication means allow students to be always connected and (massive open) online courses give great opportunities to learn based on intrinsic motivation. Also, great resources, including tutorials and catchy videos, are freely available. All these advances are intertwined with mathematics. The new jobs hold problems that we cannot yet define, requiring mathematical openness and flexibility (National Mathematics Advisory Panel, 2008). Video-sharing sites, including YouTube, are full of videos that offer useful material for those who are willing to think and embrace the creative nature of mathematics. These resources are just too good not to include them in future education and life-long learning. The only missing element is to release students' own potential to learn real mathematics. Thus, mathematics education needs a change to teach students the skills that are useful and enjoyable for them in the future.

An important stepping stone in the changing mathematics education is strongly related to a change in mindset. To get a better grip on mindset we have to define it. The concepts of fixed and growth mindsets (often called in the psychology literature "implicit theories") were introduced in 1995 (Dweck, Chiu, \& Hong, 1995; Dweck, 2006). Based on 20 years of prior research, Dweck describes two types of mindsets. A fixed mindset is the belief that one has certain talents and these remain unchanged throughout a lifetime. A growth mindset is the system of beliefs that what one can do at a moment, forms the starting point from which one can develop.

At the start of her career, Carol Dweck was trying to understand why some students were so caught up in proving their ability, while others could just let go and learn (Dweck, 2006, p. 15). The proposed mindset theory is a way for her to understand the effects of the beliefs that individuals hold about the nature of intelligence. This belief, in turn, has implications on learning and education. Importantly, she states that people have a choice: "Mindsets are just beliefs. They're powerful beliefs, but they're just something in your mind, and you can change your mind" (Dweck, 2006, p. 16).

Dweck's studies show that the effects of the different mindsets on how students learn are significant, especially in how they deal with challenges and obstacles. When students have a fixed mindset, they prefer not to get any challenges. One might think: "Suppose I fail, then people will think I am not very clever, and as this cannot change, I will stay dumb for the rest of my life." If something goes wrong, and a student has a fixed mindset, then they will feel stuck in a situation in which they cannot change anything. However, if students work with a growth mindset then they want challenges. The outcome does not really matter to them; they know and feel that it is important just to try, that they can learn from their mistakes, that their brains are at work, and that they can change (Boaler, 2016; Dweck, 2006). In addition, individuals with a growth mindset believe that not only their mathematical abilities can improve but also that their attitude and beliefs can change $(\mathrm{Ng}, 2018)$. This in itself is already very helpful while learning any new skills.

The mindset that students have is influenced by many things, including their upbringing and the school system. Parents who say "I was never able to do mathematics when I was young", influence negatively the belief system of their children (Eccles \& Jacobs, 1986), who then may develop a fixed mindset. Also, the emphasis on performance in our school system also plays an important role. High marks and quick results are seen as positive, while they can make students insecure and tend to create a fixed mindset (Dweck, 1995; Mueller \& Dweck, 1998; Dweck, 2006).

We should not think about mindset in a fixed-mindset way. One's mindset varies with context and over time (Dweck, 2006), while it impacts how one approaches and becomes involved in an activity. Recognition of the mindset by the teacher and explanation of the theory of mindset can help students change their mindset, and by that change their beliefs and attitudes towards mathematics (Boaler, 2016). 
If students believe that they can be smarter and that hard work can help them, then they are more willing to exercise (Blackwell, Trzesnieuwski, \& Dweck, 2007). Teachers can encourage students to adopt a growth mindset (Yeager \& Walton, 2011). For this goal, students and teachers need to become aware of the impact of their mindset with its challenges as well as possibilities (Dweck, 2006).

Many ideas for mathematical activities that invite students to develop a growth mindset are provided by Jo Boaler (Boaler, 2016). Interventions described in her work, and also linked to the studies of among others Yeager \& Welton (2011), Blackwell (2007), and Hattie (2008), play important roles in the present work: (1) an introduction to the theory of mindset and the importance of neuroplasticity, (2) attention to the importance of learning from mistakes, (3) growth mindset feedback in the classroom as well as individually, and finally, (4) adapting problems and activities (called collectively as tasks).

\section{First results}

In this section, we provide an overview of the first experiences that we had at Dutch educational institutes with growth-mindset mathematics teaching. Secondary schools (age group between 12 and 15 years old) and universities were involved in these studies.

\subsection{Secondary schools}

In order to investigate how the mindset of Dutch secondary-school students can be influenced in the context of mathematics learning, a large-scale research project was set up (van Hoeve, Doorman \& Veldhuis, in press). The research made use of interventions containing four elements: (1) sharing the theory about mindsets and neuroplasticity, (2) explaining the benefits of making and analyzing mistakes, (3) showing the way of giving feedback, and (4) including types of tasks favoring a growth mindset during learning mathematics (see Table 1). An important goal was to find out how these interventions can increase student participation and joy, and to what extent it improves their results.

\begin{tabular}{|l|l|l|l|}
\hline Intervention & $\begin{array}{l}\text { 1. Explanation about } \\
\text { theory of mindsets and } \\
\text { neuroplasticity the }\end{array}$ & 2. Making mistakes & 3. Feedback \\
\hline 4. Tasks & $\begin{array}{l}\text { a challenging } \\
\text { assignment without the } \\
\text { theory explained }\end{array}$ & $\begin{array}{l}\text { group assignments } \\
\text { containing mistakes; } \\
\text { "my favorite no" } \\
\text { (Alcala, 2011) }\end{array}$ & $\begin{array}{l}\text { low-floor high-ceiling } \\
\text { tasks }\end{array}$ \\
\hline
\end{tabular}

Table 1 Construction of the interventions

Currently, it is not possible to measure mindset with a brain scan, although neuroscience research aspires to do so $(\mathrm{Ng}, 2018)$. Thus, we have to rely on questionnaires, observing classes and making interviews. At the start and at the end of the interventions, students filled in a questionnaire to determine their mindset. This questionnaire consisted of 25 statements that were compiled from the literature (Blackwell, Trzesnieuwski, \& Dweck, 2007; Dweck, 2006). Students were asked to label their level of agreement to the statements on a 6-point Likert scale. The statements were divided into four types: mindset, effort belief, response to failure, and learning goals. With these different types, the impact of the intervention could be measured in different domains. For example, the questionnaire includes the following questions.

- Q1: "You have a certain amount of intelligence and you cannot do much to change it."

- Q3: “An important reason why I do my schoolwork is because I like to learn new things." 
- Q16: "If you have to work hard for a subject, you are probably not very good at it."

Besides the students questionnaires, other research activities were performed. At five schools, intervention classes were observed and students and teachers were interviewed. Finally, teachers filled in questionnaires about their mindset and about their experience during the interventions.

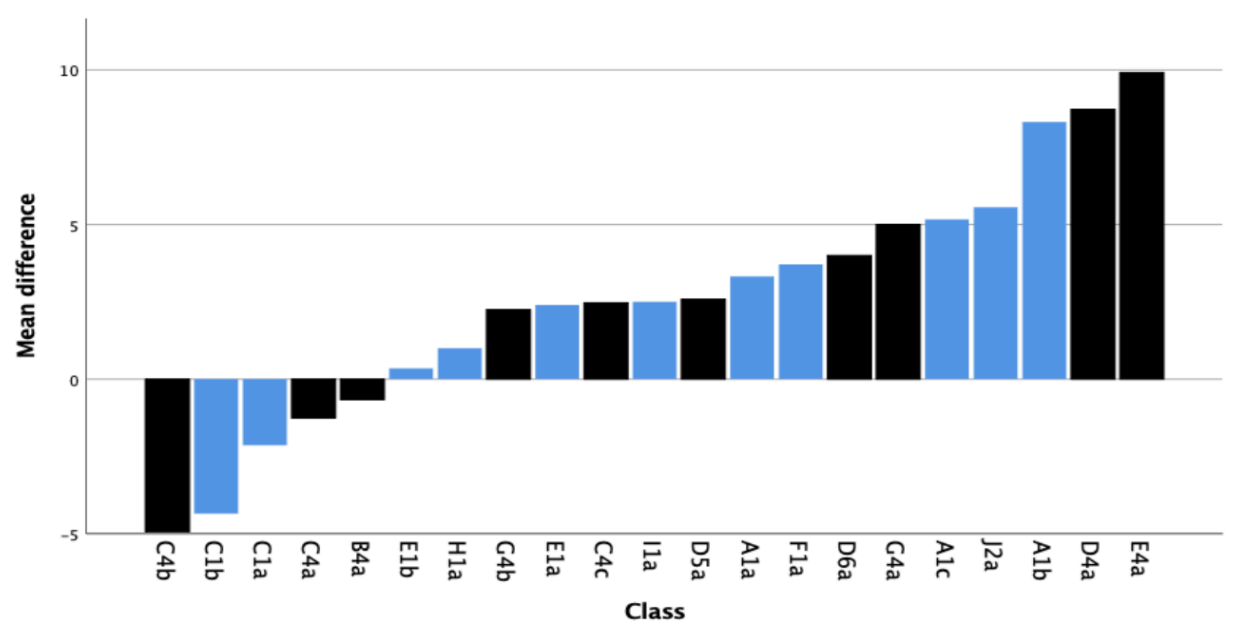

Figure 1 The mean differences in the total scores per class (van Hoeve, Doorman \& Velthuis, in press)

The intervention took place in 21 classrooms, from 10 schools throughout the Netherlands. The teachers practiced the intervention during a studyday at the Utrecht University. In total 512 students filled in both questionnaires and are included in this research. There were two rounds during the school year 2017-2018; one from October to January (eight schools) and one from February to May (two schools). The two rounds were essentially identical; for the second round some small grammar improvements were made in the tasks and some explanatory sentences were added. The interventions were developed and implemented in first grade classes of the secondary school (grade 7, $V W O^{*}$, age 12) and in upper secondary school so-called mathematics $A$ classes (mainly grade 10, HAVO, age 15). Grade 7 was chosen because these students recently switched to a new school. They start at the highest level of secondary school. To be accepted to such a school, they must have previously performed well in primary school and might have gotten labels as "high performing", which can be related to the formation of a fixed mindset. In this new environment, they were with more "high-performing" children in the classroom and had to cope with getting challenged more. This often means that the students face the challenge of not being the best anymore. Grade 10 mathematics A was chosen because this is the first year that students are divided into two groups. Mathematics A prepares for humanities and mathematics B prepares for sciences. As mathematics A is seen as easier, students having chosen this group often feel that they learn a "lower" form of mathematics and that they cannot perform well in this subject. This lower self-efficacy (see also Hattie, 2008) might indicate a fixed mindset. It is therefore interesting to see whether this can be changed by an intervention.

From class observations, interviews and mail exchanges, it has become evident that both students and teachers enjoyed the intervention. One teacher mentions: "To be able to focus so much on mindset was very inspiring". A student remarks that she has learned a lot from the lesson about the brains: "First I thought that thinking was simple and now I realize that there more happens in your head than you think. The interventions have helped me to learn. I often thought that I did not know it. And now,

${ }^{\ddagger}$ VWO (Voorbereidend wetenschappelijk onderwijs) and HAVO (Hoger algemeen voortgezet onderwijs) are two kinds of Dutch secondary schools for the same age group; however, VWO represents a higher level than HAVO. 
because of the new theory, I learned to persevere, and to ask my siblings when there are things I do not understand."

Figure 1 shows the result of the questionnaire; the mean differences are represented in the total score between before and after the interventions. It can be seen that the total scores after the interventions had lowered only in five classes, indicating a more fixed mindset. In the remaining sixteen classes the scores went up, indicating a more growth mindset. The Grade 7 classes (age 12-13) are drawn in black and Grade 10 in blue, with no clear differences emerging between the age groups.

The effect of the interventions is the most evident for the mindset score on the different scales (and not the effort belief, response to failure or learning goals). Both in Grade 7 and Grade 10 the postintervention mindset scores were higher. Also, the results of the changes of the individual students showed a pattern of more pronounced changes in the mindset score compared to the scores in the other domains. Here the change towards a growth mindset is larger in Grade 7 classes $(67.5 \%)$. This trend may indicate that the mindsets of the Grade 7 students are more intensely influenced by the interventions.

The students appreciated the entire intervention because of its content and also because of the changes in their teachers' attitudes. The questionnaire at the end of the intervention included questions about which part of the intervention the students valued the most. The interventions on "the brains" and on "the mistakes" were the most highly appreciated (results see Figure 2). One student explained: "I have to stop thinking 'this will cost too much time', or 'I really cannot do this'; instead I can persevere or try again later." Similarly, the personal interviews with students revealed that the lesson on making mistakes was experienced as the most positive. One student made the following remark after the intervention: "I did learn that making mistakes does not matter, however I still do not like it." The last question was "How did you value the attitude of the teacher towards your mindset?". Many students highly valued the change in attitude of the teacher. When being asked whether the teacher influenced his mindset, a student stated: "Yes, I think she did. For example, when she gave me the hope that I could always learn new things and that I could succeed, it did something with me. So, please never tell us 'you cannot do this'." Another student said: "The teacher explained to me very patiently that 'you do not understand it yet; we will sit together and I will explain it until you understand'. By trying to analyze my mistakes and working together to find the correct answer, she really helped me to gain trust." 


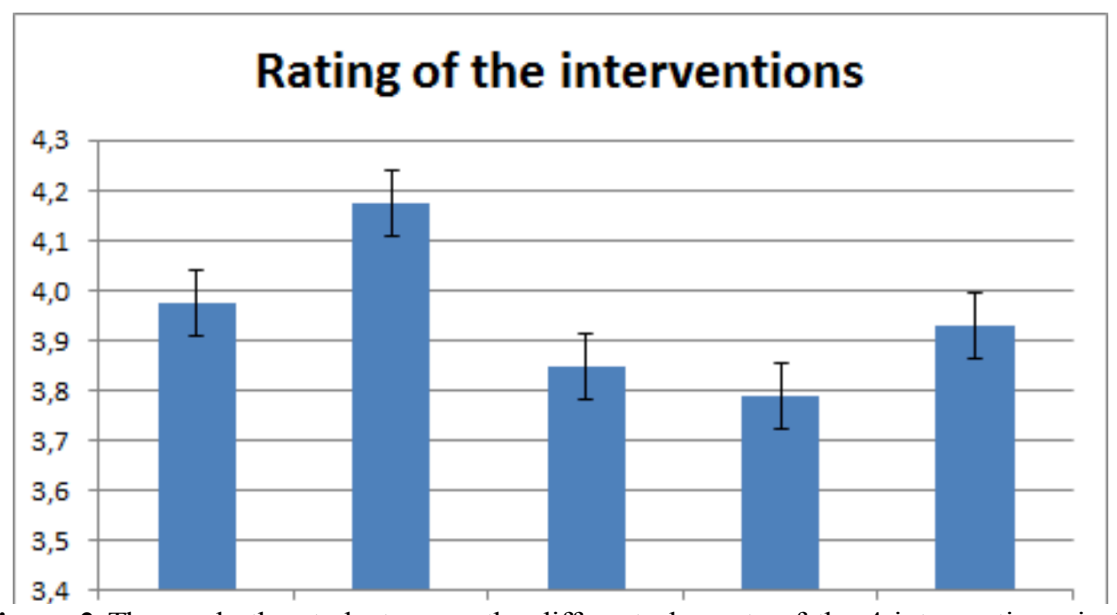

Figure 2 The grade the students gave the different elements of the 4 interventions, including the changes in attitude of the teacher (marks were from 1 to 6 , the black line indicates the standard deviation which was between 1.27 for the tasks and 1.35).

One of the most remarkable effects of the interventions was the change in language as observed and appreciated by students and teachers. In particular, teachers have to be very much aware of the effects of their words. Rattan, Good, \& Dweck (2012) show that the teacher's mindset greatly affects the mindset of their students. Teachers often try to be helpful in the form of soothing words ("it's ok, not everyone can be good at math"), but this message in fact discourages students. The same effect can be noticed when a teacher tries to make things easy for the students, saying that "we will do this quickly". Since the given problem is challenging for the student, he cannot identify with these words and thus feels unseen.

Talking about thinking with a growth mindset is a new language that both teachers and students can use. Interestingly, students can use this language when talking to teachers, talking to each other, or talking to themselves ("self-talk"). Examples of this language include the following sentences.

- "You cannot do it YET."

- "It is not STUPID to make a mistake."

- "Synapses fire when you learn."

- "Sir, that is a fixed-mindset comment you are making."

This language gives hope, as Chodron (2006) also remarks: "Failure can be the portal to creativity, to learning something new, to having a fresh perspective". With spoken words, we also get a glimpse of the thoughts that are in the heads of our students. By getting help from the teacher in adapting their words, they also change their self-talk, their attitude and their mindset. For example, when a student says "I am doing my calculations so foolishly", the teacher can advise: "Do you hear what you are saying to yourself? Is this helpful? Does it make you happy? How can we change what you are saying to yourself so that it becomes helpful?"

It is also a challenge for a teacher to attend to their own words. How often do you say "but" or "actually"? How often do you say or think "they will never learn"? What do you hear others say, for example, during report meetings? A relevant question is, therefore, how teachers start to remind each other and help each other when noticing fixed-mindset ideas. It is a nice new language to discuss delicate matters in teams as well. For instance, when you hear a colleague say halfway during an academic year that "this class will never be good at math", you can say in a friendly way: "That sounds like a fixed-mindset statement, doesn't it? How can I help?". 
Such changes in language are powerful. With regard to our secondary-school research, all teachers were very much involved in the intervention. During the interviews they made comments like: "As a mentor, and as a teacher in mathematics, I can now discuss more easily how important it is to learn from your mistakes. I also attend to my own mistakes more consciously, and I explain how I deal with them." Another teacher writes that she has become more careful with her words. She tries to avoid even small, seemingly unimportant words like "just" (e.g. "just make your assignments"), as these may disempower her classes. One teacher reported that "I find it a real challenge; you have to pay attention to all the words the students are saying, also the words they say to each other and to themselves. To be able to do that with the whole class is not yet possible for me. Nonetheless, with a few students separately I do succeed."

\subsection{Universities}

The objective of the research at the universities was to explore the need and the possibilities of growth-mindset mathematics teaching at this level. The focus was on developing an introductory course, called Open Maths, that would open students in two ways. First, they should see themselves as worthwhile thinkers within mathematics (and indirectly, in other sciences), and second, they should see mathematics as a subject of many possibilities. So, students open up to mathematics and mathematics opens up to students.

The study load of the Open Maths course was 50 hours, and it was given two times. First at the Radboud University and then at the Open University of the Netherlands. Twelve computer science students attended each of these courses. At Radboud, nine of them are bachelor students, two premasters and one master student. There were nine Dutch and three foreign students, and nine males and three females. Nine students finished all homework assignments and three students only some of those. At the Open University, all of them were bachelor students. There were ten Dutch and two Belgian students, and five males and seven females. Eight students finished all assignments at the Open University, while four submitted only a subset of those.

The main goals of the course for the students were to get enthusiastic about mathematics, to learn more about what mathematics actually is, and finally, to develop learning strategies at a university level. For each of these goals, there was a set of preceding homework assignments and classroom sessions.

First, students engaged with the idea of "Mathematics and I". They had to write a maths history, in which they reported on their prior experiences with mathematics and maths education (see also in Section 3). During the first classroom session, students reflected on their histories. Besides that, several activities helped to "open up" mathematics. With very simple visual and computational problems, students experienced some fundamental aspects of doing mathematics. First of all, they were surprised to see that everybody thinks differently - even about the simplest things. Among others, number talks (Humphreys \& Parker, 2015) were applied throughout the course. This type of activity can generate classroom discussions with high engagement and participation. As a result, students discovered that their own thinking is unique and valuable. Moreover, they understood that it is worthwhile collaborating, as others can give new perspectives. Apart from mathematical problems, they also learnt about scientific results from neuroscience and psychology. Brain plasticity and growth mindset (see more detail in Section 2) gave students confidence that they can develop their skills throughout their lifetime. By the end of the class, students could solve some problems related to growing visual patterns. The strong relation between visual and algebraic representations played an important role here (see also Figure 3 from the homework following this class). 


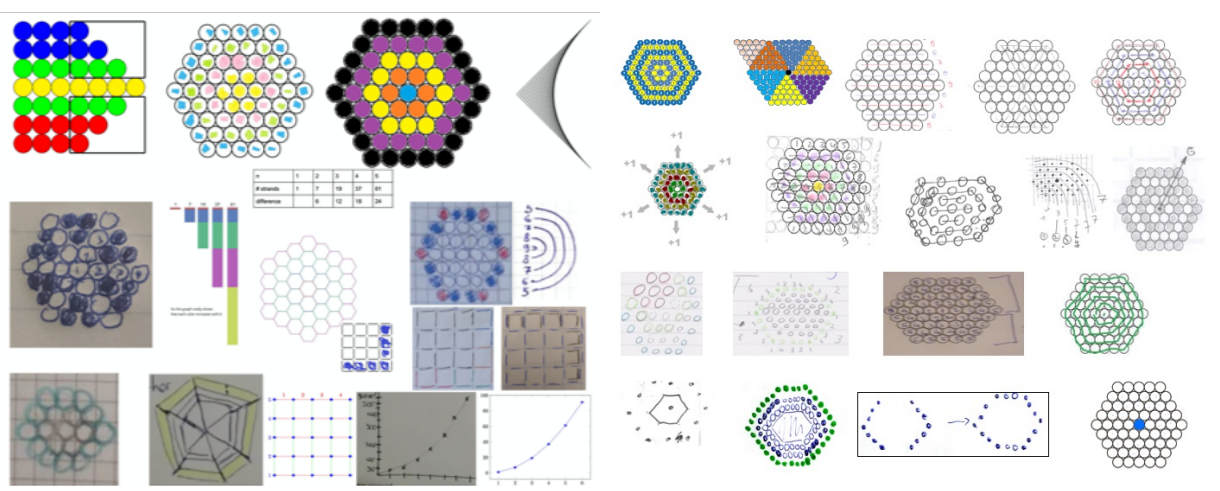

Figure 3 Various representations by students of algebraic problems

The second goal was that students start recognizing what mathematics actually is. Several homework assignments served this goal. Students had to read some relevant texts, then to investigate patterns and find general algebraic formulas for them. Finally, they watched and reflected on TED talks about mathematics. They also had to make their own descriptions of "patterns" and "mathematics".

During classroom sessions, students investigated low-floor, high-ceiling problems (Boaler, 2016). These problems offer multiple solution strategies and allow a rich exploratory experience. They could make observations and reason about them and find more and more advanced regularities. Making conjectures, discovering that some of them are incorrect, while others can be proven are very important steps of doing real mathematics. An additional activity was to practice number talks on each other. This was also a preparatory step for managing a number talk in their own interview, which was one of the following homework assignments.

The third goal was to develop strategies for learning mathematics and for solving maths problems. The assignments included geometric and algebraic investigations. Besides these, students had to watch two visual and deeply mathematical videos (from the YouTube channels 3Blue1Brown and Numberphile) and apply their understanding in follow-up questions. For instance, they had to prove that a cylinder section is an ellipse or they had to approximate the square root of pi with continued fractions. Notably, even though students had not known the fundamental concepts in these videos (including a conic section and a continued fraction) before this course, everybody was able to write valuable ideas, and some of them gave full solutions and/or original insights.

The classroom discussion was about learning and solution strategies. Students could collect and discuss their own ideas first. They had experienced quite some new strategies during the course, which they started including in their toolbox. With the help of an online tool, the students collected strategies, e.g., "accept that sometimes you need help from others", "Try to help other people understand so you yourself will understand it better" or "First read all the assignments on the exam so my brain is already working on the problems". Furthermore, students had their own general ideas about studying at the university, e.g. "Watch YouTube videos on the topics", "Starting at the simple exercises, and move gradually to the more difficult ones." And some are really personal: "Locking myself up, put on classic music and go into a sort of coffee fed trans where I can do weeks' worth of stuff in hours", "Praying", "Putting the book under my pillow". On a more serious note, we also discussed other learning strategies from research. Most importantly, students learned about Barbara Oakley's two brain states during learning; the focused mode and the diffuse mode (Oakley, 2014).

Additionally, students could analyze their interviews in group discussions. An interesting observation is how students became much more confident when they were placed in the role of a mathematics interviewer. Their reflection reports show that they found it amusing how others think in a similar way about mathematics as they had thought before the Open Maths course, e.g. "She had some 
difficulties describing mathematics, but after some effort she described it as a tool. Which I found interesting because that's exactly the way I looked at mathematics before this course."

Finally, we closed the course by discussing our experiences.

To measure the effects of the Open Maths course at both universities, we used expression cards that students had to arrange in the order of relevance that made sense for them. The cards displayed activities that might be important during mathematics learning. The six expressions are taken from the report "Everybody Counts" (National Research Council, 1989). One of the transitions that the report posits is that "[t]he public perception of mathematics is shifting from that of a fixed body of arbitrary rules to a vigorous active science of patterns. [...] This transformation suggests changes in both curricular content and instructional style." It follows that this style "involves renewed effort to focus on:

- Seeking solutions, not just memorizing procedures;

- Exploring patterns, not just learning formulas;

- Formulating conjectures, not just doing exercises."

So, the cards that students received ("seeking solutions", "memorizing procedures", "exploring patterns", "learning formulas", "formulating conjectures", "doing exercises") had no prior order or structure and their task was to arrange them.

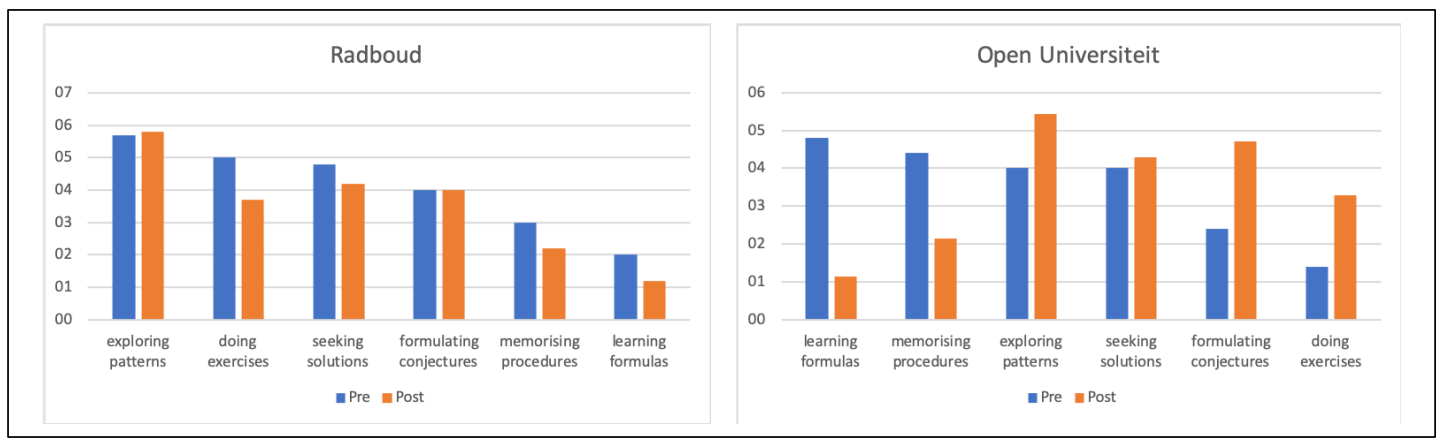

Figure 4 What activities are important for students when learning mathematics before and after the Open Maths course? (The blue and orange columns show the average relevance of an activity before and after, respectively.)

Figure 4 shows the effects of the Open Maths course at both universities. (The columns are arranged at each university according to the initial measurement in decreasing order.) The results are somewhat in line with our expectations, but the data also show surprising aspects. After the course, all students seem to agree that memorization is less important in mathematics than they had thought beforehand. Furthermore, following the course, both groups of students think that the three most important activities when learning mathematics are exactly the three desired focuses from the report "Everybody Counts": "exploring patterns", "formulating conjectures", and "seeking solutions" (National Research Council, 1989). However, there are unexpected, huge differences between the two universities. Students at the Open University experienced clearly a greater effect by the course. Here memorization-related activities dropped from the most important to the least important ones, while the above-mentioned desired activities jumped to the top three. At the Radboud University, there are no such pronounced changes. We note, nevertheless, that the Radboud students have also thoroughly profited from the course in other aspects, which this measure cannot indicate. For instance, they have developed new skills (e.g., problem-solving techniques and learning strategies) and more positive attitude - as we know it from reflection homework assignments and interviews. In summary, the course achieved its goal in terms of students' understanding of learning mathematics, but the road to get there may vary greatly among students. 


\subsection{Connection between the secondary-school and universities research}

The two research projects were set up and carried out in different ways. On the one hand, the secondary-school interventions (see Section 4.1) were performed by different mathematics teachers throughout The Netherlands. The tasks that were included in the interventions, were only slightly modified with respect to the problems and exercises that students are used to. On the other hand, the university research is based on a completely new mathematics course at two Dutch universities (see Section 4.2). Furthermore, this distinct course contained real mathematical-mindset activities, selfreflection assignments, and new tasks. Also, the methods by which the mindset and the results of the research were measured are not comparable.

The organization of the two interventions was also necessarily different because of the study context. On the one hand, an intervention at the university could easily be organized as a separate (optional) course. Students (in this case, computer science students) were able to register freely to improve their mathematical thinking and learning skills. Moreover, the researchers themselves could give the classes. On the other hand, at the secondary-school level, the researchers had to embed the intervention in the curriculum. This resulted in a hierarchical organizational structure, in which the researchers coordinated and trained the teachers. The actual class interventions were performed by the teachers.

However, in both cases it was very clear that the explanation of the theory of mindset, the focus on mistakes and feedback, and the changes in tasks (small or large) resulted in positive changes in student attitude towards mathematics.

From the assignment "mathematical history" that the university students had to do, some important elements can be learned that secondary schools should be informed about. Students report that there was a lack of creativity and real challenges for them in the secondary schools. This is in contrast with the fact that creativity and challenges are important elements of mathematics. Moreover, students talk about (time) pressure and a focus on marks, which do not improve mathematical skills; see also (Boaler, 2015). The little attention on motivation is also not appreciated by students; their desire is that motivation should be an important part of mathematics.

\section{Further research}

Based on this research it can be concluded that changing the teaching towards growth mindset gives many positive results. Students are enthusiastic, they learn a new language, they learn to understand what mathematics is, and they develop a more positive attitude to learning mathematics and to learning in general. To continue improving the education both at secondary schools and at universities, further research is needed.

Questionnaires. One of the challenges in the research on mindset is the measurement of mindset itself. It is mainly done with filling in questionnaires by grading statements. However, these statements may not be clear for the research subjects. For example, a statement is: "You can learn new things, but you can't really change your basic intelligence." A difficulty is that the meaning of "intelligence" seems to be different in the US and in Europe, which influences the answers. This affects the reliability of the measurements. Therefore, we should be aware of the interpretations in different countries. While an IQ test is mostly used as a snapshot, the measurement of mindsets is often used to assess how much a group has changed as a result of an intervention. (Interestingly, the original objective of an IQ test was similar, Antonson, 2010.) Another difficulty with the questionnaires is that there are often too few statements and the statements are too simple. When students are informed about mindset, and have to fill in a second questionnaire, they know what the "good" ("growth") answers are and as they want to please the researcher or the teacher, they tend to fill in the socially desirable answers. To counter this effect in our research, a more extensive questionnaire was used, together with other techniques, such as lesson 
observations, interviews, and assignments in the classes; these provided opportunities for students to explain how they experienced the intervention elements or how their attitude had changed. Maybe in the near future mindset can be measured with neuroscience and then this problem might disappear. Until neuroscience has solved the problem, we have to improve the research methodology with regard to mindset questionnaires.

Neuroscience. In the interventions images about neurons firing were used to explain neuroplasticity. However, these pictures are simplifications of a process that is still little understood. The role of neuroplasticity in learning requires further research. Promising new results are being published (e.g., Herbet, Maheu, Costi, Lafargue, \& Duffau, 2016, Sarrasin et al., 2018, Lin, Imada, \& Kuhl, 2019) and they should be brought to our lessons as quickly as possible.

In her article, Betsy Ng (2018) explains that brain plasticity refers to the ability of our brain to change throughout our life. It is thereby important to understand how our brain changes if we undergo a growth-mindset intervention and whether there are changes in our intrinsic motivation as well. $\mathrm{Ng}$ puts more emphasis on the way neuroscience can be used to understand motivation than to measure mindset; thus, further research on the latter is needed.

Daly et al. (2019) have promising results as well in how neuroscience can help understand the role of changes in teaching. In their research with university science students, EEG scans show evidence that mathematical mindsets increase student motivation. Their methodology included the comparison of brain activity of learners attempting mathematical problems prepared in two ways. Calculation mathematics tasks were given in the usual, closed way or in a more open, "mathematical mindsets" way. Although the modifications in the tasks are small and just partly reflect Boaler's suggestions, the results are already positive; the brain has become more active. Therefore, we suggest new, improved research and new good teaching practices in this area. If the interventions in this article are combined with the tasks according to Boaler (2016), even more positive results are expected.

Pedagogy. Mindset research and interventions can vary greatly. The intervention may include only one questionnaire (Huang, Zhang, \& Hudson, 2018) without additional input from the teachers; alternatively, it may include some input from the teachers such as the explanation of the theory of mindset and how the brains work (Yeager \& Dweck, 2012); finally, there may be more extensive interventions (similar to this research). Further research is needed to find optimal ways of adapting pedagogy with a growth mindset. Depending on age, school, teachers, classes, time and money, etc., various interventions can be desired. From the research about secondary schools, which deployed interventions with different teachers, one element was important yet not expected at the start; the crucial role of the teacher. As soon as the teachers understood deeply the mindset theory, they changed their teachings; see also e.g. (Rattan et al., 2012, Rau, 2016). Therefore, this should also be the object of more extensive research.

Tasks. Assignments are an important part of mathematics education. In this research, the extent of modifications of the lesson materials varied from small (secondary schools) to large (university). A large-scale improvement can be expected if teachers learn and implement these small adjustments. It does not cost much lesson time, and research indicates that already these modifications amount to more student enthusiasm, more active participation and better results. To continue applying and to further expand these positive results from research into practical classroom settings, it is important to support teachers. This includes creating new problem sets for various mathematics topics, to share best practices for modifying simple tasks into more open, low-floor, high-ceiling tasks, and possibly developing entirely new curricula. 


\section{Discussion}

For centuries the joy of mathematics, proper sense-making of mathematical problems, and a deep understanding of mathematical concepts and relations, have been a privilege for a selected group of people. Because of research results from psychology, neuroscience and pedagogy, mathematics now becomes accessible for a wider audience. This is important not only as students are required to progress efficiently in their studies using the ever changing and developing technological environment, but also because future generations will face problems that we cannot even predict yet. Therefore, mathematics taught and learned with a growth mindset, may be a disruptive innovation in education that is desperately needed for our students.

Research in the USA indicates that mindset interventions are especially effective for certain groups; for example, for women (Good et al., 2012) and for Afro-American students (Aronzon et al, 2002). Girls and women appreciate the reassuring knowledge that mathematics ability can be acquired any time. They can then withstand negative stereotypes, and their sense of belonging in mathematics expands as well as their wish to continue dealing with mathematics in the future. In our research, there were similar indications; nonetheless, we have to investigate this in more detail.

The concept of mindsets might be seen as a separate theory from others: self-efficacy, motivation, or 21 st century skills. However, it is all about creating the best environment for our students to learn, and for ourselves to develop. We should not see these aspects as unconnected, but as various parts and new insights of the same challenge; to grow, to learn, and to be.

Why are we learning mathematics? How can we use the results of this research? How can we extend our knowledge? These questions should be investigated both by the teachers and the students. Already at the secondary-school level (or even earlier), students could work with low-floor, high-ceiling problems. Furthermore, students at all levels should get the chance to explore mathematics. They can do this if they know that mathematics can be learned, and that mathematics is not about memorization and reproduction. As a result, they always dare to ask why they learn what they learn. Finally, the results of this study at two educational levels can positively affect each other. Similarly to the ways problems were opened up at the university courses, tasks could already be opened at lower educational levels. In turn, the use of the "mindset language" and kind words used at the secondary schools, can also contribute to a more growth-mindset culture at the universities.

\section{Acknowledgments}

We would like to thank Michiel Doorman from the University of Utrecht for his contributions to this work. We would also like to acknowledge all the students and teachers at the secondary schools and universities that have worked with the interventions. We have learned so much from all of you. Furthermore, we thank the help of Marc Schoolderman and Paulus Meessen for their valuable assistance in the Open Maths courses. We would like to remember Monique Bakker (†) from the Ster College in Eindhoven, who was full of enthusiasm with respect to this research.

\section{References}

Alcala, L. (2011). My favorite no. [Video file]. Retrieved from https://www.youtube.com/watch?v=uuDjke-p4Co.

Anderson, R., Boaler, J., \& Dieckmann, J. (2018). Achieving elusive teacher change through challenging myths about learning: A blended approach. Education Sciences, 8(3), 98. 
Antonson, AE. (2010). Stanford-Binet Intelligence Scale. In: Clauss-Ehlers CS, ed. Encyclopedia of Cross-Cultural School Psychology. Springer, Boston, MA.

Aronson, J., Fried C.B. \& Good, C (2002): Reducing the effects of stereotype threat on African American college students by shaping theories of intelligence. Journal of experimental social psychology 38, 113-125.

Boaler, J. (2015). Fluency without fear: Research evidence on the best ways to learn math facts. Reflections, 40(2), 7-12.

Boaler, J. (2016). Mathematical mindsets: Unleashing students' potential through creative math, inspiring messages and innovative teaching. John Wiley \& Sons.

Bostwick, K.C.P., Martin, A.J., Collie, R.J. \& Durksen, T.L (2019). Growth orientation predicts gains in middle and high school students' mathematics outcomes over time. Contemporary educational psychology 58, 213-227.

Chödrön, P. (2006). The places that scare you - a guide to fearlessness. Boston, USA: Shambhala.

Daly, I., Bourgaize, J., and Vernitski, A., Mathematical mindsets increase student motivation: Evidence from the EEG. Trends in Neuroscience and Education 15 (2019) 18-28

Draganski, B., Gaser, C., Busch, V., Schuierer, G., Bogdahn, U., \& May, A. (2004). Neuroplasticity: changes in grey matter induced by training. Nature, 427(6972), 311-312.

Drijvers, P. H. M. (2015). Denken over wiskunde, onderwijs en ICT: Inaugurale rede.

Dweck, C.S. (2006). Mindset, The new psychology of success. New-York, USA: Random House USA.

Dweck, C.S. (2015). Carol Dweck revisits the growth mindset, Educational Week, 22 september 2015, Available from: https://www.edweek.org/ew/articles/2015/09/23/carol-dweck-revisits-thegrowth-mindset.html

Eccles, J. S., \& Jacobs, J. E. (1986). Social forces shape math attitudes and performance. Signs: Journal of women in culture and society, 11(2), 367-380.

Good, C., Rattan, A. \& Dweck C.S. (2012). Why do women opt out? Sense of belonging and women's representation in mathematics. Journal of Personality and Social Psychology vol 102, no4, 700-717

Herbet, G., Maheu, M., Costi, E., Lafargue, G., \& Duffau, H. (2016). Mapping neuroplastic potential in brain-damaged patients. Brain, 139(3), 829-844.

Huang, X., Zhang,J. and Hudson, L. (2018) Impact of math self-efficacy, math anxiety, and growthmindset on math and science career interest for middle school students: the gender moderating effect. European Journal of Psychology of Education, 34, 621-640

Humphreys, C., \& Parker, R. (2015). Making number talks matter: Developing mathematical practices and deepening understanding, grades 4-10. Stenhouse Publishers.

Isik, M. (2017) Wees Onzichtbaar. Anthos Amsterdam

Koncepciya razvitiya (2013). Retrieved from: https://rg.ru/2013/12/27/matematika-site-dok.html

Larina, G. and Markina, V. (2019). Hidden mechanisms of differentiation: Teachers'beliefs about student diversity. Journal of Mathematics Teacher Education, https://doi.org/10.1007/s10857-01909436-1

Lin, J. F. L., Imada, T., \& Kuhl, P. K. (2019). Neuroplasticity, bilingualism, and mental mathematics: A behavior-MEG study. Brain and cognition, 134, 122-134

National Mathematics Advisory Panel. (2008). Foundations for success: The final report of the National Mathematics Advisory Panel. US Department of Education.

National Research Council. (1989). Everybody counts: A report to the nation on the future of mathematics education. National Academies Press. https://doi.org/10.17226/1199.

$\mathrm{Ng}$, B. (2018). The neuroscience of growth mindset and intrinsic motivation. Brain sciences, $8(2)$, 20. https://doi.org/10.3390/brainsci8020020.

Oakley, B. A. (2014). A mind for numbers: How to excel at math and science (even if you flunked algebra). TarcherPerigee. 

Press

Polya, G. (1957). How to solve it; a new aspect of mathematical method. (2nd ed.) Princeton Univ.

Rattan, A., Good, C. \& Dweck, C.S. (2012). 'It's ok - Not everyone can be good at math': instructors with an entity theory comfort (and demotivate) students. Journal of Experimental Social Psychology, 48, 731-737.

Rau, A. (2016). Exploring the Influence of Teacher Language on Fourth Grade Students' Mindsets: A Multi-Case Study. The Qualitative Report, 21(9), 1684-1707. Retrieved from https://nsuworks.nova.edu/tqr/vol21/iss9/8

Sarrasin, J. B., Nenciovici, L., Foisy, L. M. B., Allaire-Duquette, G., Riopel, M., \& Masson, S. (2018). Effects of teaching the concept of neuroplasticity to induce a growth mindset on motivation, achievement, and brain activity: A meta-analysis. Trends in neuroscience and education, 12, 22-31.

van Hoeve, M., Doorman, M., \& Veldhuis, M. (in press). How can teachers influence their students' (mathematical) mindset? Proc. of Eleventh Congress of the European Society for Research in Mathematics Education (CERME11).

Van Merriënboer, J. J., \& Kirschner, P. A. (2012). Ten steps to complex learning: A systematic approach to four-component instructional design. Routledge.

Woollett, K., \& Maguire, E. A. (2011). Acquiring "the Knowledge" of London's layout drives structural brain changes. Current biology, 21(24), 2109-2114.

World Economic Forum. (2018). The Future of Jobs Report 2018 [Insight Report]. Retrieved from http://www3.weforum.org/docs/WEF_Future_of_Jobs_2018.pdf.

Yeager, D.S., \& Dweck, C.S. (2012). Mindsets that promote resilience: when students believe that personal characteristics can be developed. Educational Psychologist, 47 (4), 302-314. 